\title{
Indicadores biológicos associados ao ciclo do fósforo em solos de Cerrado sob plantio direto e plantio convencional
}

\author{
Roberto Guimarães Carneiro(1), lêda de Carvalho Mendes ${ }^{(2)}$, Paulo Emílio Lovato( ${ }^{(3)}$, \\ Arminda Moreira de Carvalho ${ }^{(2)}$ e Lúcio José Vivaldi(4)
}

\begin{abstract}
(1)Emater, Parque Estação Biológica, Ed. Emater, Asa Norte, CEP 70770-220, Brasília, DF. E-mail: geagr@emater.df.gov.br (2)Embrapa Cerrados, Caixa Postal 08223, CEP 73310-970 Planaltina, DF. E-mail: mendesi@cpac.embrapa.br, arminda@unb.br (3)Universidade Federal de Santa Catarina, Dep. de Engenharia Rural, Florianópolis, SC. E-mail: plovato@mbox1.ufsc.br (4)Universidade de Brasília, Dep. de Estatística, CEP 70910-900 Brasília, DF. E-mail: vivaldi@unb.br
\end{abstract}

Resumo - O objetivo deste trabalho foi avaliar a influência do plantio direto, do preparo convencional do solo e de plantas de cobertura sobre indicadores biológicos associados ao ciclo do fósforo $(\mathrm{P})$. O trabalho foi realizado em três áreas adjacentes, num Latossolo Vermelho-Amarelo, distribuídas da seguinte maneira: área I, dois anos de experimentação, comparando esses sistemas de plantio; área II, seis anos de experimentação e área III, Cerrado nativo. Em julho/1998 e janeiro/1999, avaliaram-se: o P da biomassa, populações de fungos e bactérias totais e solubilizadores de fosfato e a atividade da fosfatase ácida, nas profundidades de $0-5$ e de $5-20 \mathrm{~cm}$. A atividade da fosfatase e a ocorrência de fungos e bactérias solubilizadoras nas áreas com plantio direto foram significativamente superiores às das áreas com plantio convencional, na profundidade de $0-5 \mathrm{~cm}$. $\mathrm{O}$ tempo de implantação acentuou as diferenças entre plantio direto e convencional quanto aos indicadores avaliados. O P da biomassa diminuiu no tratamento plantio direto com nabo forrageiro (Raphanus sativus) da área II. Os fungos solubilizadores aumentaram na presença de guandu (Cajanus cajan) e nabo forrageiro, e as bactérias solubilizadoras aumentaram na presença de guandu. $\mathrm{O}$ solo sob vegetação nativa apresentou maior atividade da fosfatase em relação ao das áreas cultivadas, evidenciando a importância da mineralização do P orgânico nesse ecossistema.

Termos para indexação: P da biomassa microbiana, fosfatase ácida, microrganismos solubilizadores de fosfato, culturas de cobertura.

\section{Soil biological indicators associated to the phosphorus cycle in a Cerrado soil under no-till and conventional tillage systems}

\begin{abstract}
The objective of this work was to evaluate the effects of no-till, conventional tillage and cover crops on biological indicators associated to the P cycle. The work was carried out on three adjacent areas on a RedYellow Oxisol: area I, a two-year experiment comparing the two management systems; area II, a six-year experiment, and area III, a native Cerrado vegetation. The soil was sampled at two depths (0-5 cm and 5-20 cm) in July/1998 and January/1999. The biological indicators evaluated were microbial biomass $\mathrm{P}$, acid phosphatase activity, phosphate-solubilizing and total soil fungi and bacteria. Acid phosphatase activity and number of phosphatesolubilizing microorganisms, at the $0-5 \mathrm{~cm}$ depth, were significantly greater in the no-till soil, as compared to the conventional tillage. Differences between the tillage systems, regarding the biological indicators evaluated, were more pronounced in area II in which the no-till system had been established for a longer period. Microbial $\mathrm{P}$ decreased in the no-till Raphanus sativus treatment. P-solubilizing fungi increased in the presence of Cajanus cajan and Raphanus sativus, whereas the P-solubilizing bacteria increased in the presence of $C$. cajan. Highest activities of acid phosphatase were detected in the soil under native vegetation, evidencing the importance of organic P mineralization in this ecosystem.
\end{abstract}

Index terms: microbial biomass $\mathrm{P}$, acid phosphatase, phosphate solubilizing microorganisms, cover crops.

\section{Introdução}

Os microrganismos do solo desempenham papel fundamental no ciclo biogeoquímico do fósforo $(\mathrm{P})$ e na sua disponibilidade para as plantas, mediante o fluxo de $\mathrm{P}$ pela biomassa microbiana, a solubilização do $\mathrm{P}$ inorgânico, a mineralização do $\mathrm{P}$ orgânico e a associa- ção entre plantas e fungos micorrízicos (Paul \& Clark, 1996).

O P imobilizado na biomassa microbiana pode ser liberado pela ruptura das células microbianas, promovida por variações climáticas e de manejo de solo, e, também, por causa das interações com a microfauna que, ao se alimentar de microrganismos, libera diversos nu- 
trientes no solo (Buchanan \& King, 1992). O P contido na biomassa funciona, portanto, como uma proteção desse nutriente, diminuindo sua fixação por períodos prolongados em minerais do solo (Paul \& Clark, 1996) e aumentando a eficiência da adubação fosfatada pela imobilização de parte do $\mathrm{P}$ do fertilizante na biomassa (Tisdale et al., 1993; Guerra et al., 1995; He et al., 1997). Dessa forma, o conteúdo e o fluxo de $\mathrm{P}$ por meio da biomassa microbiana desempenham importante papel como reservatório de $\mathrm{P}$, podendo atingir valores equivalentes ou, às vezes, superiores à absorção desse nutriente pelas plantas (Brookes et al., 1984; Singh et al., 1989).

Bactérias, fungos e actinomicetos, envolvidos nos processos de solubilização do $\mathrm{P}$ inorgânico, excretam ácidos orgânicos que atuam dissolvendo diretamente o material fosfático ou quelando os cátions que acompanham o ânion fosfato (Kucey, 1983). A população de microrganismos solubilizadores de fosfato e sua capacidade de solubilização estão intimamente relacionadas ao tipo e ao manejo do solo (Kucey, 1983; Nahas et al., 1994b).

Além do P da biomassa microbiana, da atuação dos microrganismos solubilizadores de fosfato e dos fungos micorrízicos, a produção de enzimas, como as fosfatases ácidas e alcalinas por microrganismos, é responsável pela mineralização do P orgânico (Dick \& Tabatabai, 1993). Os microrganismos e as plantas são responsáveis pela produção das fosfatases ácidas, enquanto as alcalinas parecem ser produzidas somente por microrganismos (Tabatabai, 1994). De acordo com Dick \& Tabatabai (1993), os microrganismos seriam as fontes mais expressivas de fosfatases no solo, por causa da sua grande biomassa, alta atividade metabólica e curto tempo de vida, com várias gerações por ano, permitindo a produção e a liberação de quantidades elevadas de enzimas extracelulares em comparação com as plantas.

No bioma Cerrado, apesar de várias pesquisas sobre fungos micorrízicos (Miranda \& Miranda, 1997), pouco se conhece sobre outros processos microbiológicos associados ao ciclo do $\mathrm{P}$ e sobre o impacto de diferentes sistemas de manejo do solo nesses processos.

O objetivo deste trabalho foi avaliar a influência do plantio direto, do preparo convencional do solo e de plantas de cobertura sobre indicadores biológicos associados ao ciclo do fósforo.

\section{Material e Métodos}

O estudo foi realizado num Latossolo Vermelho-Amarelo argiloso, no Distrito Federal, com clima Tropical Estacional (Aw) conforme classificação de Köppen. Nas estações seca (julho de 1998) e chuvosa (janeiro de 1999), foram coletadas amostras de solo em duas profundidades $(0-5 \mathrm{~cm}$ e 5-20 cm), em três áreas adjacentes: área I, com dois anos de experimentação, comparando os sistemas de plantio direto (PD) e preparo convencional do solo (PC); área II, com seis anos de experimentação e área III, sob vegetação nativa de Cerrado. As áreas I e II foram desmatadas em 1978 e cultivadas durante oito anos com culturas anuais sob preparo de solo convencional. De 1986 até a instalação dos experimentos (em 1992/93 na área II e em 1997/98 na área I), elas foram deixadas em pousio e anualmente as gramíneas (vegetação predominante nas duas áreas) eram manejadas pelo uso de roçadeiras.

$\mathrm{Na}$ área I, o experimento iniciou-se em 1997 e consistia no estudo dos efeitos do PD, recém-implantado, em relação ao PC, constando de uma sucessão de milho e culturas de cobertura. O delineamento experimental foi de blocos casualizados com três repetições, com parcelas subdivididas. As parcelas $(12 \times 30 \mathrm{~m})$ eram constituídas pelas espécies vegetais de cobertura: guandu (Cajanus cajan), mucuna-cinza (Mucuna pruriens) e vegetação espontânea (testemunha) e as subparcelas $(12 \times 15 \mathrm{~m})$ pelos sistemas de manejo: PD e PC (uma aração e duas gradagens).

Visando ao estabelecimento de uma cronosseqüência com diferentes tempos de estabelecimento do plantio direto, também foram feitas avaliações numa área experimental adjacente (área II) onde, desde 1992, o sistema de PC comumente praticado na região do Cerrado (uma aração e duas gradagens, sem o uso de culturas de cobertura na entressafra) é comparado a sistemas de plantio direto com culturas de cobertura. Essa área consiste de duas faixas com $320 \mathrm{~m}$ de comprimento por $50 \mathrm{~m}$ de largura, uma com plantio direto (PD) e outra com plantio em sistema convencional de preparo do solo (PC). A faixa de PD é subdividida em parcelas de $1.700 \mathrm{~m}^{2}$, nas quais várias culturas de cobertura são instaladas no final da estação chuvosa, em sucessão ao milho ou à soja. As faixas de PC são mantidas em pousio até o preparo do solo (uma aração e duas gradagens) para a safra seguinte. Foram coletadas amostras de solo nos tratamentos de sucessão milho/nabo forrageiro (Raphanus sativus)/soja em PD (nabo forrageiro em 
PD), milho/milheto (Pennisetum americanum)/soja em PD (milheto em PD) e milho/soja em preparo de solo convencional (PC). A terceira área avaliada correspondeu a um solo sob vegetação nativa de Cerrado, utilizado como referência.

As amostras na profundidade $0-5 \mathrm{~cm}$ foram coletadas com pá, com abertura de uma minitrincheira da qual foram retiradas fatias de solo com $5 \mathrm{~cm}$ de espessura por $30 \mathrm{~cm}$ de largura. Na profundidade $5-20 \mathrm{~cm}$, as amostras foram coletadas com trado tipo holandês, no mesmo local da amostragem de $0-5 \mathrm{~cm}$. Nas áreas I (experimento iniciado em 1997), II (iniciado em 1992) e III (Cerrado nativo), as amostras compostas de solo foram obtidas pela mistura de 10,30 e 20 subamostras, respectivamente, e mantidas a $4^{\circ} \mathrm{C}$ até o momento das análises. As propriedades químicas dos solos dessas áreas são apresentadas na Tabela 1 .

Nas análises microbiológicas, as amostras foram passadas em uma peneira com malha de $4,0 \mathrm{~mm}$, removendo-se resíduos de plantas e raízes. Avaliaram-se o conteúdo de $\mathrm{P}$ da biomassa microbiana, as populações de fungos e bactérias totais e solubilizadores de fosfatos (solubilizadores de P) e a atividade da enzima fosfatase ácida. O P da biomassa foi determinado pelo método da fumigação e extração (Brookes et al., 1982). Amostras de 5,0 g de solo foram distribuídas em frascos de vidro, num total de oito por tratamento. Metade das amostras foi fumigada por 48 horas num dessecador de 5,0 L contendo $25 \mathrm{~mL}$ de clorofórmio. A extração do P foi realizada pela adição de $50 \mathrm{~mL}$ de uma solução de $\mathrm{NaHCO}_{3}$ $0,5 \mathrm{M}(\mathrm{pH} \mathrm{8,5)} \mathrm{e} \mathrm{sua} \mathrm{quantificação} \mathrm{pelo} \mathrm{método}$ colorimétrico do molibdato-ácido ascórbico. Para corri- gir a fixação de $\mathrm{P}$ inorgânico (Pi) durante a extração, foi estimada a taxa de recuperação de uma quantidade conhecida de $\mathrm{P}$ adicionado ao solo juntamente com o extrator $\mathrm{NaHCO}_{3}$. No cálculo do $\mathrm{P}$ da biomassa, adotou-se o fator de correção (Kp) de 0,4 (Brookes et al., 1982).

As contagens das populações de fungos e bactérias totais e solubilizadores de fosfato foram realizadas por meio de diluições seriadas (três placas por diluição) em meio BDAL (batata, dextrose, ágar e extrato de levedura). Nos meios de cultura de bactérias e fungos, antes da autoclavagem, o $\mathrm{pH}$ foi corrigido para 7,0 e 5,5, respectivamente. No meio de cultura dos fungos, acrescentaram-se $70 \mathrm{mg} \mathrm{L}^{-1}$ de rosa-bengala e $30 \mathrm{mg} \mathrm{L}^{-1} \mathrm{de}$ sulfato de estreptomicina. As contagens dos microrganismos solubilizadores de $\mathrm{P}$ foram realizadas segundo Kucey (1983). Após a autoclavagem, foram adicionadas aos meios de cultura soluções estéreis de $\mathrm{K}_{2} \mathrm{HPO}_{4}$ (30 mL L-1) e $\mathrm{CaCl}_{2}\left(60 \mathrm{~mL} \mathrm{~L}^{-1}\right)$ na concentração de $10 \%(\mathrm{p} / \mathrm{v})$ para promover a formação de um precipitado de fosfato de cálcio. O aparecimento de um halo transparente em volta das colônias caracterizou a presença de solubilizadores de fósforo.

A atividade da fosfatase ácida foi determinada conforme Tabatabai (1994), baseada na determinação colorimétrica do $p$-nitrofenol liberado a partir da ação das fosfatases, após incubação do solo em solução tamponada de $p$-nitrofenilfosfato $0,05 \mathrm{M}$.

Os dados da área I foram submetidos à análise de variância. As profundidades e as épocas de amostragem foram consideradas como subsubparcelas e subsubsubparcelas, respectivamente, de acordo com

Tabela1. Características químicas dos solos na área I, com dois anos de avaliação dos sistemas plantio direto (PD) e convencional (PC); área II, com seis anos de avaliação e na área III, sob vegetação nativa de Cerrado, nas profundidades de 0-5 cm e 5-20 cm.

\begin{tabular}{|c|c|c|c|c|c|c|c|c|c|c|c|c|}
\hline \multirow[t]{2}{*}{ Tratamento $^{(1)}$} & \multicolumn{2}{|c|}{$\begin{array}{c}\mathrm{pH} \\
\text { (água) }\end{array}$} & \multicolumn{2}{|c|}{$\begin{array}{c}\mathrm{Al} \\
\left(\mathrm{cmol}_{\mathrm{c}} \mathrm{dm}^{-3}\right)\end{array}$} & \multicolumn{2}{|c|}{$\begin{array}{c}\mathrm{H}+\mathrm{Al} \\
\left(\mathrm{cmol}_{\mathrm{c}} \mathrm{dm}^{-3}\right)\end{array}$} & \multicolumn{2}{|c|}{$\begin{array}{c}\mathrm{Ca}+\mathrm{Mg} \\
\left(\mathrm{cmol}_{\mathrm{c}} \mathrm{dm}^{-3}\right)\end{array}$} & \multicolumn{2}{|c|}{$\begin{array}{c}\mathrm{P} \\
\left(\mathrm{mg} \mathrm{kg}^{-1}\right)\end{array}$} & \multicolumn{2}{|c|}{$\begin{array}{c}\mathrm{K} \\
\left(\mathrm{mg} \mathrm{kg}^{-1}\right)\end{array}$} \\
\hline & $0-5$ & $5-20$ & $\overline{0-5}$ & $5-20$ & $0-5$ & $5-20$ & $0-5$ & $5-20$ & $0-5$ & $5-20$ & $0-5$ & $5-20$ \\
\hline & & \multicolumn{11}{|c|}{ Área I } \\
\hline Vegetação espontânea-PD & 5,7 & 5,6 & 0,1 & 0,1 & 4,6 & 4,6 & 2,9 & 2,8 & 6,9 & 3,1 & 114,0 & 39,7 \\
\hline Vegetação espontânea-PC & 5,7 & 5,7 & 0,1 & 0,1 & 4,9 & 4,4 & 3,1 & 3,0 & 5,6 & 4,4 & 143,0 & 40,0 \\
\hline Guandu-PD & 5,7 & 5,6 & 0,1 & 0,1 & 4,7 & 4,6 & 3,1 & 3,0 & 7,6 & 3,6 & 120,0 & 44,0 \\
\hline Guandu-PC & 5,7 & 5,7 & 0,1 & 0,1 & 4,4 & 4,3 & 2,9 & 2,7 & 5,0 & 3,3 & 140,0 & 42,7 \\
\hline Mucuna-PD & 5,5 & 5,8 & 0,1 & 0,1 & 4,7 & 4,7 & 3,2 & 3,1 & 6,2 & 2,8 & 127,0 & 40,3 \\
\hline \multirow[t]{2}{*}{ Mucuna-PC } & 5,8 & 5,8 & 0,1 & 0,1 & 4,3 & 4,2 & 3,1 & 3,3 & 4,3 & 2,7 & 163,0 & 44,0 \\
\hline & & \multicolumn{11}{|c|}{ Áreas II e III } \\
\hline Milheto-PD & 5,9 & 5,6 & 0,0 & 0,1 & 4,5 & 5,2 & 3,6 & 2,4 & 22,4 & 4,8 & 238,0 & 58,5 \\
\hline Nabo forrageiro-PD & 6,2 & 5,7 & 0,0 & 0,2 & 3,8 & 5,6 & 4,4 & 2,5 & 13,8 & 4,7 & 233,0 & 66,0 \\
\hline $\mathrm{PC}$ & 5,7 & 5,9 & 0,1 & 0,1 & 4,5 & 4,3 & 3,1 & 3,0 & 7,7 & 6,4 & 90,0 & 35,0 \\
\hline Cerrado nativo & 4,9 & 4,9 & 0,9 & 0,5 & 7,2 & 6,4 & 0,2 & 0,2 & 1,0 & 0,9 & 31,0 & 24,0 \\
\hline
\end{tabular}


Milliken \& Johnson (1992). Foram consideradas significativas as interações e os efeitos que apresentaram no teste $\mathrm{F}$ nível de significância igual ou inferior a $10 \%$. Utilizou-se o teste $\mathrm{t}(1 \%, 5 \%$ e $10 \%$ de probabilidade), na comparação das médias. Os graus de liberdade do resíduo (composto) foram calculados pela fórmula de Satterthwaite (1946) e as variâncias dos contrastes conforme Cochran \& Cox (1957). Na análise das contagens dos microrganismos solubilizadores de fosfato e totais, os valores $(\mathrm{x})$ foram transformados em $(\mathrm{x}+0,5)^{0,5}$.

A inclusão das áreas II e III (cerrado nativo) nas avaliações teve um caráter observativo, pois constituía uma oportunidade única de estudo, especialmente na Região do Cerrado, onde existem poucos experimentos de longa duração com sistema de plantio direto. Uma vez que a ausência de um delineamento experimental apropriado incluindo as três áreas não permitia aplicação dos testes estatísticos usuais, os valores obtidos nessas áreas foram utilizados para auxiliar na interpretação dos valores dos indicadores biológicos obtidos na área I. Para isso, várias medidas foram adotadas (avaliações em parcelas grandes e homogêneas e uso de amostras compostas formadas por elevado número de subamostras) para reduzir o erro experimental e aumentar a representatividade das amostras de solo coletadas nas áreas II e III.

\section{Resultados e Discussão}

O conteúdo de $\mathrm{P}$ na biomassa microbiana do solo variou de 2 a $20 \mu \mathrm{g} \mathrm{g}^{-1}$ (Tabela 2), assemelhando-se aos valores de 7 a $14 \mu \mathrm{g} \mathrm{g}^{-1}$ e de 8,7 a $25,0 \mu \mathrm{g} \mathrm{g}^{-1}$ constatados por Guerra et al. (1995) no Rio de Janeiro e Conte et al. (2002), no Rio Grande do Sul, respectivamente.

$\mathrm{Na}$ área I, as amostras da estação chuvosa (janeiro) tiveram média $\left(9,9 \mu \mathrm{g} \mathrm{g}^{-1}\right)$ significativamente superior (teste $\mathrm{t}, \mathrm{p}<0,05)$ à da estação seca $\left(3,4 \mu \mathrm{g} \mathrm{g}^{-1}\right)$. A interação entre profundidade e época também foi significativa. $\mathrm{Na}$ amostragem realizada em julho (estação seca), os teores de $\mathrm{P}$ da biomassa nas profundidades 0-5 cm e 5-20 cm não diferiram significativamente entre si. Na amostragem de janeiro (estação chuvosa), o P da biomassa na profundidade de $5-20 \mathrm{~cm}\left(12,3 \mu \mathrm{g} \mathrm{g}^{-1}\right)$ foi superior (teste $\mathrm{t}, \mathrm{p}<0,1)$ à da profundidade $0-5 \mathrm{~cm}$ $\left(7,4 \mu \mathrm{g} \mathrm{g}^{-1}\right)$. Como na semeadura do milho o adubo fosfatado foi colocado $7 \mathrm{~cm}$ abaixo da superfície do solo, é possível que esse efeito esteja relacionado à imobilização de parte do $\mathrm{P}$ do fertilizante na biomassa microbiana, conforme Tisdale et al. (1993) e Conte et al. (2002).
Nas análises dos dados referentes à estação chuvosa, em algumas repetições analíticas, houve interferência nas determinações do $\mathrm{P}$ da biomassa na profundidade de 5-20 cm causada pelos adubos fosfatados utilizados na adubação do milho. Entretanto, as variações de $\mathrm{P}$ da biomassa ocorridas entre as duas épocas de amostragem, equivalentes a $13 \mathrm{~kg} \mathrm{ha}^{-1} \mathrm{de} \mathrm{P}$ nos primeiros $20 \mathrm{~cm}$ de solo no caso do Cerrado nativo, indicam que a biomassa microbiana pode representar importante reservatório de $\mathrm{P}$ lábil para as plantas nas condições do Cerrado. Buchanan \& King (1992) observaram incrementos no $\mathrm{P}$ da biomassa no outono e no inverno e decréscimos nesses valores no final da primavera, implicando a liberação de mais de $29 \mathrm{~kg} \mathrm{ha}^{-1}$ de $\mathrm{P}$ no solo, o que representou um pouco mais do que foi extraído pela cultura do milho.

Sistemas agrícolas com menor perturbação do solo conseguem manter maiores teores de $\mathrm{P}$ na biomassa microbiana (Brookes et al., 1984; Rheinheimer et al., 2000), como verificado nas amostras do PD na área I, em que a interação entre manejo e época foi significativa (Tabela 3). Na época chuvosa e com grande atividade biológica, o $\mathrm{P}$ contido na biomassa microbiana do solo no PD (média de 11,4 $\mu \mathrm{g} \mathrm{g}^{-1}$ ) foi significativamente superior (teste $\mathrm{t}, \mathrm{p}<0,1$ ) ao do PC (média de $8,3 \mu \mathrm{g} \mathrm{g}^{-1}$ ). $\mathrm{O}$ manejo do solo pode ser, portanto, fator determinante no fluxo de $\mathrm{P}$ por intermédio da biomassa microbiana, sendo necessária melhor compreensão sobre sua dinâmica e contribuição para a nutrição das plantas.

$\mathrm{Na}$ área I, não houve efeitos das espécies vegetais avaliadas (guandu e mucuna) em relação ao $\mathrm{P}$ da biomassa, conforme também verificado por Rheinheimer et al. (2000) no Sul do Brasil. Na área II, o tratamento nabo forrageiro em PD apresentou, na profundidade 0-5 cm, baixos valores de $\mathrm{P}$ da biomassa em comparação ao tratamento milheto em PD, nas duas épocas avaliadas. Na estação chuvosa, esses valores foram inferiores até mesmo aos do PC, nas duas profundidades avaliadas (Tabela 2). Como o nabo forrageiro é uma espécie que não se associa com fungos micorrízicos (Smith \& Read, 1997), é possível que a diminuição do conteúdo de $\mathrm{P}$ na biomassa microbiana nesse tratamento possa estar associada à diminuição da população de fungos micorrízicos.

Conte et al. (2002), no Rio Grande do Sul, e Srivastava \& Singh (1991), na Índia, observaram maiores teores de $\mathrm{P}$ da biomassa em áreas nativas do que em áreas cultivadas. Gijsman et al. (1997) não observaram diferenças no $\mathrm{P}$ da biomassa entre áreas de savanas nati- 


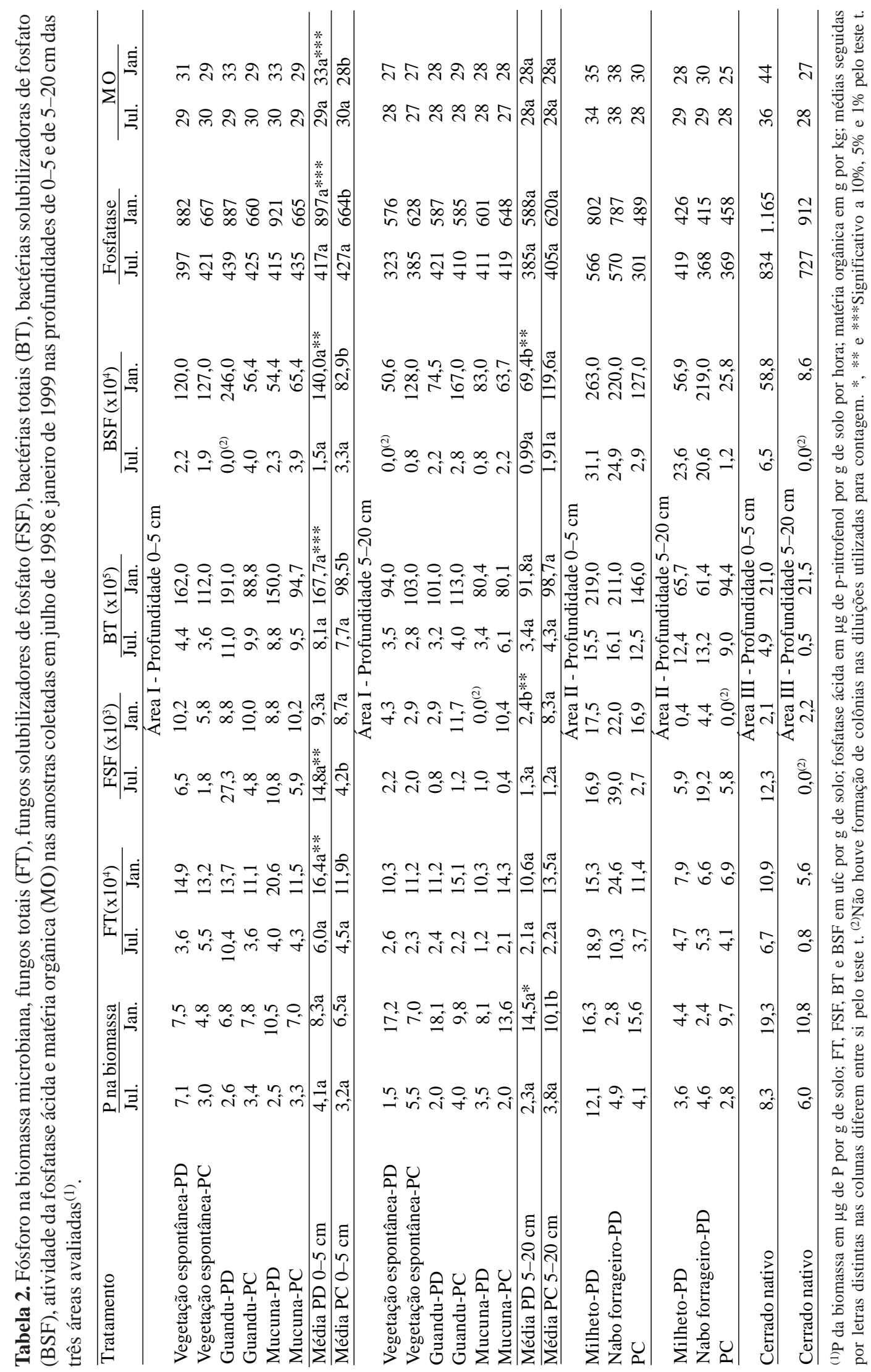


vas na Colômbia e áreas com cinco anos de monocultura de arroz. No presente trabalho, as diferenças no $\mathrm{P}$ da biomassa entre a área sob vegetação nativa e as áreas cultivadas não foram consistentes. Como a aplicação de fertilizantes fosfatados pode estimular o acúmulo de P na biomassa microbiana (Conte et al., 2002), os dados deste trabalho sugerem que, provavelmente, esse efeito também possa variar em razão da época e da profundidade de coleta das amostras, assim como do sistema de manejo e da planta de cobertura.

Nas contagens de fungos solubilizadores de fosfato (FSF), houve interação entre manejo e época na área I (Tabela 3). Na estação seca (julho), o número de FSF no PD foi de $8,1 \times 10^{3}$ ufc $^{-1}$ de solo, significativamente superior (teste $\mathrm{t}, \mathrm{p}<0,1)$ ao do PC $\left(2,7 \times 10^{3} \mathrm{ufc} \mathrm{g}^{-1}\right.$ de solo). Na estação chuvosa não houve diferença significativa entre esses sistemas de manejo. A interação entre manejo e profundidade também foi significativa (Tabela 3). Na profundidade de $0-5 \mathrm{~cm}$, a diferença entre PD e PC foi significativa (teste $t, p<0,1$ ) com o PD propiciando a ocorrência de maiores populações de fungos totais (FT) $\left(11,2 \times 10^{4} \mathrm{ufc} \mathrm{g}^{-1}\right.$ de solo) e solubilizadores de fosfato $\left(12,1 \times 10^{3}\right.$ ufc g $^{-1}$ de solo) em relação ao PC $\left(8,2 \times 10^{4}\right.$ ufc g $^{-1}$ de solo de fungos totais e $6,4 \times 10^{3}$ ufc g$^{-1}$ de solo de fungos solubilizadores). A maior influência do PD ocorre próximo à superfície do solo onde a palhada permanece após o ciclo das plantas de cobertura e da cultura principal. Esse ambiente é propício aos fungos, decompositores primários de resíduos vegetais na superfície do solo, especialmente em condições de baixa umidade (Hendrix et al., 1986). Os resultados da área II (seis anos de PD) confirmaram os obtidos na área I. Na estação seca e na profundidade de $0-5 \mathrm{~cm}$, o PD, independentemente da cultura de cobertura, proporcionou aumento médio de dez vezes no número de FSF e de quatro vezes no número de $\mathrm{FT}$, em relação ao $\mathrm{PC}$ (Tabela 2).

Apesar do curto período de utilização de plantas de cobertura na área I, as contagens de FT e FSF foram influenciadas pelas espécies vegetais em razão do manejo de solo adotado e da época de amostragem, ou seja, a interação plantas de cobertura, manejo e época foi significativa (Tabela 3). Na estação seca, o guandu influenciou significativamente (teste $t, p<0,1$ ) as contagens de FT no sistema PD, apresentando uma população $\left(6,4 \times 10^{3}\right.$ ufc g $^{-1}$ de solo) superior à dos tratamentos com vegetação espontânea $\left(3,1 \times 10^{3} \mathrm{ufc} \mathrm{g}^{-1}\right.$ de solo) e mucuna-cinza $\left(2,6 \times 10^{3}\right.$ ufc g $^{-1}$ de solo), que não diferiram entre si. Na estação chuvosa, nos tratamentos sob PC, o guandu influenciou a população de FSF (teste t, $\mathrm{p}<0,1)$, apresentando contagem significativamente superior $\left(10,8 \times 10^{3} \mathrm{ufc} \mathrm{g}^{-1}\right.$ de solo) à do tratamento com vegetação espontânea $\left(4,4 \times 10^{3}\right.$ ufc g $^{-1}$ de solo). Abboud (1986) também verificou maiores populações de FSF em parcelas com guandu quando comparadas a outros cinco adubos verdes, sugerindo, como possível explicação, a composição dos exsudatos liberados na rizosfera do guandu. $\mathrm{Na}$ área II, as maiores contagens de FSF foram observadas no tratamento nabo forrageiro em PD, principalmente, na época seca (Tabela 2), sugerindo uma

Tabela 3. Resumo da análise de variância para espécies vegetais de cobertura/adubos verdes (Cob), sistemas de manejo do solo (Man), profundidades (Prof) e épocas de amostragem (Ep) no experimento com dois anos de implantação do plantio direto (área I).

\begin{tabular}{|c|c|c|c|c|c|c|c|}
\hline \multirow[t]{2}{*}{ Fontes de variação } & \multicolumn{6}{|c|}{ Níveis de probabilidade $(\mathrm{P}>\mathrm{F})^{(1)}$} & \multirow[b]{2}{*}{ MO } \\
\hline & $\mathrm{P}$ da biomassa & FSF & FT & BSF & $\mathrm{BT}$ & Fosfatase & \\
\hline$\overline{\mathrm{Cob}}$ & 0,8120 & 0,5116 & 0,7145 & 0,1350 & 0,6697 & 0,4664 & 0,9815 \\
\hline Man & 0,3225 & 0,9069 & 0,6528 & 0,1618 & 0,1781 & 0,0002 & 0,0166 \\
\hline Cob x Man & 0,5447 & 0,5629 & 0,7562 & 0,1304 & 0,9322 & 0,0422 & 0,2417 \\
\hline Prof & 0,0321 & 0,0001 & 0,0001 & 0,4595 & 0,0297 & 0,0001 & 0,0001 \\
\hline Cob x Prof & 0,5814 & 0,2467 & 0,6925 & 0,4491 & 0,9390 & 0,6430 & 0,6881 \\
\hline Man x Prof & 0,9624 & 0,0142 & 0,0039 & 0,0681 & 0,0943 & 0,0001 & 0,1682 \\
\hline Cob x Man x Prof & 0,2712 & 0,2128 & 0,0574 & 0,0909 & 0,8422 & 0,7274 & 0,7819 \\
\hline Ep & 0,0001 & 0,0723 & 0,0001 & 0,0001 & 0,0001 & 0,0001 & 0,3870 \\
\hline Cob x Ep & 0,4759 & 0,8912 & 0,1908 & 0,0531 & 0,3275 & 0,6156 & 0,8314 \\
\hline Man x Ep & 0,0954 & 0,0159 & 0,9367 & 0,7290 & 0,0778 & 0,0112 & 0,0465 \\
\hline Cob x Man x Ep & 0,2380 & 0,1000 & 0,0607 & 0,1690 & 0,7657 & 0,9735 & 0,5602 \\
\hline Prof x Ep & 0,0093 & 0,2773 & 0,0419 & 0,8102 & 0,3040 & 0,0016 & 0,0035 \\
\hline Cob x Prof x Ep & 0,4962 & 0,2989 & 0,1353 & 0,4683 & 0,5568 & 0,8582 & 0,7818 \\
\hline Man x Prof x Ep & 0,2176 & 0,9865 & 0,1049 & 0,0339 & 0,0467 & 0,0055 & 0,0401 \\
\hline
\end{tabular}

${ }^{(1)}$ FSF: fungos solubilizadores de fosfato; FT: fungos totais; BSF: bactérias solubilizadoras de fosfato; BT: bactérias totais; fosfatase: atividade da fosfatase ácida; MO: teor de matéria orgânica. 
associação entre nabo forrageiro e FSF, de forma a compensar as desvantagens nutricionais proporcionadas pela ausência de associação micorrízica nessa espécie vegetal (Smith \& Read, 1997).

Em relação às contagens de bactérias solubilizadoras de fosfato (BSF) e de bactérias totais (BT), na área I, a interação entre manejo, profundidade e época de amostragem foi significativa (Tabela 3 ). Na amostragem de julho, não houve influência dos sistemas de manejo em nenhuma profundidade. Entretanto, em janeiro, na profundidade $0-5 \mathrm{~cm}$, as contagens de BT e BSF no PD foram superiores em relação ao PC (Tabela 2). Na profundidade 5-20 cm, com relação ao número de $\mathrm{BSF}$, o resultado foi oposto, com superioridade do PC em relação ao PD (Tabela 2). Resultados semelhantes foram obtidos por Doran (1980), que atribuiu o comportamento inverso das contagens de bactérias, nas duas profundidades, aos efeitos relacionados à incorporação dos resíduos vegetais nas áreas de plantio convencional. $\mathrm{Na}$ área II, desde a amostragem de julho já havia diferenciação entre os tratamentos sob PD e PC nas duas profundidades. Nessa amostragem, na profundidade 0-5 cm, as contagens de BSF nos tratamentos milheto em PD e nabo forrageiro em PD foram 11 e 9 vezes superiores em relação ao PC, e na profundidade 5-20 cm essa diferença foi de 20 e 17 vezes, respectivamente (Tabela 3). Na estação chuvosa, embora menos acentuada, essa diferença persistiu nas duas profundidades.

$\mathrm{Na}$ área I, com dois anos de implantação do PD, a interação entre plantas de cobertura e época foi significativa em relação às bactérias solubilizadoras de fosfato (Tabela 3). Independentemente do sistema de manejo e da profundidade, na amostragem de janeiro, o guandu proporcionou aumento significativo (teste $t, p<0,01$ ) nas contagens de BSF (136x $10^{4}$ ufc g $^{-1}$ de solo) em relação à mucuna $\left(66,6 \times 10^{4}\right.$ ufc g $^{-1}$ de solo) demonstrando seu potencial como planta condicionadora de maiores populações dessas bactérias. As contagens de BSF nos tratamentos com vegetação espontânea $\left(106 \times 10^{4}\right.$ ufc g $^{-1}$ de solo) também foram menores, porém a diferença não foi significativa.

Em geral, os resultados das contagens de fungos e bactérias solubilizadoras de fosfato e de fungos e bactérias totais, na área de Cerrado nativo, foram inferiores aos das áreas cultivadas. Tais diferenças podem estar relacionadas à calagem e à adubação do solo que, ao aumentarem o $\mathrm{pH}$ e a disponibilidade de nutrientes nas áreas cultivadas, podem favorecer o desenvolvimento desses organismos (Nahas et al., 1994a). Entretanto, a interpretação desses resultados também deve levar em conta as limitações do método de contagem em placas, o qual seleciona as espécies que formam colônias e se desenvolvem bem no meio de cultura escolhido (cultiváveis), em detrimento de outras que não se adaptam ou simplesmente não crescem no mesmo meio (Kucey, 1983). De acordo com Torsvik et al. (1990), apenas pequena parte dos microrganismos do solo $(0,1 \%$ a $0,5 \%)$ cresce em meios de cultura. É possível, portanto, que no Cerrado nativo, haja, em maior número, microrganismos que não crescem em meio de cultura comparado às áreas cultivadas.

$\mathrm{Na}$ área I, a interação entre manejo, profundidade e época foi significativa em relação à atividade da fosfatase ácida (Tabela 3). Não houve diferença de atividade da fosfatase entre os sistemas de manejo na estação seca (julho) em nenhuma das profundidades de amostragem (Tabela 2). Entretanto, na estação chuvosa, a atividade da fosfatase no sistema PD foi significativamente superior à do PC na profundidade $0-5 \mathrm{~cm}$ (Tabela 2). Na área II, com seis anos de implantação do PD, os tratamentos milheto em PD e nabo forrageiro em PD apresentaram, em média, na profundidade $0-5 \mathrm{~cm}$, níveis de atividade da fosfatase $89 \%$ e $62 \%$ superiores aos observados no PC nas amostragens de julho e janeiro, respectivamente (Tabela 2). Na profundidade 5-20 cm, não foram constatadas diferenças entre os sistemas de manejo em nenhuma das duas épocas de amostragem.

O tempo de implantação acentuou as diferenças entre os sistemas de plantio direto e plantio com preparo convencional do solo em relação à atividade da fosfatase ácida e às populações de microrganismos solubilizadores de fosfato. As maiores populações de fungos e bactérias (solubilizadores e totais) e as maiores atividades da fosfatase ácida, na profundidade de $0-5 \mathrm{~cm}$, nos tratamentos sob PD (áreas I e II) estão relacionadas à ausência de revolvimento do solo e ao conseqüente acúmulo de matéria orgânica no $\mathrm{PD}$. $\mathrm{Na}$ área $\mathrm{I}$, a interação entre manejo, profundidade e época foi significativa em relação à matéria orgânica (Tabela 3), indicando que nas amostras coletadas em janeiro, os teores de matéria orgânica da profundidade $0-5 \mathrm{~cm}$ nos tratamentos sob PD foram superiores em relação aos obtidos nas áreas sob PC (Tabela 2). Na área II, foram observados maiores teores de matéria orgânica na profundidade de $0-5 \mathrm{~cm}$ nos tratamentos sob PD, em comparação ao PC, nas duas épocas de amostragem (Tabela 2). Resultados semelhantes também foram obtidos por Doran (1980), Deng \& Tabatabai (1997), Dick et al. 
(1988), Nahas et al. (1994b) e Mendes et al. (2003). Além de estimular os microrganismos e ser, ao mesmo tempo, fonte de energia e nutrientes, a matéria orgânica também atua protegendo e mantendo as enzimas do solo em suas formas ativas, pela formação de complexos enzima-compostos húmicos (Deng \& Tabatabai, 1997). No caso da fosfatase ácida, as maiores atividades nos tratamentos sob PD da Área II, na profundidade 0-5 cm, também podem estar relacionadas à aplicação localizada dos fertilizantes fosfatados. Embora essa aplicação localizada resulte em maior concentração de $\mathrm{P}$ nos $5 \mathrm{~cm}$ iniciais do PD (Tabela 1), a inibição das fosfatases não é tão acentuada como no PC, onde os fertilizantes são misturados ao solo (Conte et al., 2002; Mendes et al., 2003).

Embora o tipo de vegetação, por meio da quantidade e qualidade de seu material orgânico, possa influir na atividade enzimática do solo (Dick et al., 1988; Dick \& Tabatabai, 1993), não houve efeito significativo das espécies vegetais de cobertura na atividade da fosfatase ácida nas áreas cultivadas. $\mathrm{Na}$ área $\mathrm{I}$, apesar de a interação entre espécies de cobertura e manejo ter sido significativa (Tabela 3), as diferenças entre as espécies de cobertura foram pouco expressivas (Tabela 2), o que pode estar relacionado à baixa produção de matéria seca por essas espécies.

Os elevados níveis de atividade da fosfatase no Cerrado nativo associados aos baixos teores de $\mathrm{P}$ (Mehlich I), que variaram de 1,0 a $0,3 \mathrm{ppm}$ nas profundidades 0-5 cm e 5-20 cm, evidenciam que a mineralização do $\mathrm{P}$ orgânico nas áreas nativas é um importante processo de disponibilização desse elemento, conforme também verificado por Conte et al. (2002) no Sul do Brasil.

O estabelecimento de índices e parâmetros sensíveis no acompanhamento do impacto do uso do solo em relação à sua fertilidade e à sua qualidade como um todo têm sido objeto de vários estudos (Dick, 1994; TrasarCepeda et al., 1998). Entre os indicadores avaliados no presente trabalho, a atividade da fosfatase ácida merece destaque por sua sensibilidade em detectar alterações provocadas no solo pelos sistemas de manejo e sazonalidade do clima e, portanto, poderá ser útil em programas de avaliação da qualidade do solo, ampliando o enfoque sobre fertilidade do solo com a inclusão do componente biológico.

\section{Conclusões}

1. O sistema de plantio direto proporciona um ambiente mais favorável à atividade da fosfatase ácida e à ocorrência de fungos e bactérias solubilizadores de fosfato e totais, na profundidade de $0-5 \mathrm{~cm}$.

2. O guandu estimula a ocorrência de fungos e bactérias solubilizadores de fosfato.

\section{Agradecimentos}

A Osmar Teago de Oliveira, Emílio J. Taveira, Maria das Dores Silva, Odete J. dos Santos e Vilderete C. Alves, pela coleta das amostras de solo e análises laboratoriais.

\section{Referências}

ABBOUD, A.C.S. Eficiência da adubação verde associada a fosfato natural de Patos de Minas. 1986. 298p. Dissertação (Mestrado) - Universidade Federal Rural do Rio de Janeiro, Seropédica.

BROOKES, P.C.; POWLSON, D.S.; JENKINSON, D.S. Measurement of microbial biomass phosphorus in soil. Soil Biology and Biochemistry, v.14, p.319-329, 1982.

BROOKES, P.C.; POWLSON, D.S.; JENKINSON, D.S. Phosphorus in the soil microbial biomass. Soil Biology and Biochemistry, v.16, p.169-175, 1984.

BUCHANAN, M.; KING, L.D. Seasonal fluctuations in soil microbial biomass carbon, phosphorus, and activity in no-till and reduced-chemical-input maize agroecosystems. Biology and Fertility of Soils, v.13, p.211-217, 1992.

COCHRAN, W.G.; COX, G.M. Experimental designs. New York: J. Wiley, 1957. 611p.

CONTE, E.; ANGHINONI, I.; RHEINHEIMER, D.S. Fósforo da biomassa microbiana e atividade de fosfatase ácida após aplicação de fosfato em solo no sistema plantio direto. Revista Brasileira de Ciência do Solo, v.26, p.925-930, 2002.

DENG, S.P.; TABATABAI, M.A. Effect of tillage and residue management on enzyme activities in soils - 3: phosphatases and arylsulfatase. Biology and Fertility of Soils, v.24, p.141-146, 1997.

DICK, R.P. Soil enzyme activities as indicators of soil quality. In: DORAN, J.W.; COLEMAN, D.C.; BEZDICEK, D.F.; STEWART, B.A. (Ed.). Defining soil quality for a sustainable environment. Madison: Soil Science Society of America, 1994. p.107-124.

DICK, R.P.; RASMUSSEN, P.E.; KERLE, E.A. Influence of long term residue management on soil enzyme activities in relation to soil chemical properties of a wheat-fallow system. Biology and Fertility of Soils, v.6, p.159-164, 1988.

DICK, W.A.; TABATABAI, M.A. Significance and potential uses of soil enzymes. In: METTING JUNIOR, F.B. (Ed.). Soil microbial ecology applications in agricultural and environmental management. New York: M. Dekker, 1993. p.95-127.

DORAN, J.W. Soil microbial and biochemical changes associated with reduced tillage. Soil Science Society of America Journal, v.44, p.765-771, 1980. 
GIJSMAN, A.J.; OBERSON, A.; FRIESEN, D.K.; SANZ, J.I.; THOMAS, R.J. Nutrient cycling through microbial biomass under rice-pasture rotations replacing native savanna. Soil Biology and Biochemistry, v.29, p.1433-1441, 1997.

GUERRA, J.G.M.; FONSECA, M.C.; ALMEIDA, D.L.; DEPOLLI, H.; FERNANDES, M.S. Conteúdo de fósforo da biomassa microbiana de um solo cultivado com Brachiaria decumbens stapf. Pesquisa Agropecuária Brasileira, v.30, p.543-551, 1995.

HE, Z.L.; WU, J.; O’DONNELL, A.G.O.; SYERS, J.K. Seasonal responses in microbial biomass carbon, phosphorus and sulphur in soils under pasture. Biology and Fertility of Soils, v.24, p.421428, 1997.

HENDRIX, P.F.; PARMELEE, R.W.; CROSSLEY JUNIOR, D.A.; COLEMAN, D.C.; ODUM, E.P.; GROFFMAN, P.M. Detritus food webs in convencional and no-tillage agroecosystems. Bioscience, v.36, p.374-380, 1986.

KUCEY, R.M.N. Phosphate-solubilizing bacteria and fungi in various cultivated and virgin Alberta soils. Canadian Journal of Soil Science, v.63, p.671-678, 1983.

MENDES, I.C.; SOUZA, L.V.; RESCK, D.V.S.; GOMES, A.C. Propriedades biológicas em agregados de um LE sob plantio convencional e direto no Cerrado. Revista Brasileira de Ciência do Solo, v.27, p.435-443, 2003.

MILLIKEN, G.A.; JOHNSON, D.E. Analysis of messy data: designed experiments. New York: Chapman \& Hall, 1992. v.1.

MIRANDA, J.C.C. de; MIRANDA, L.N. Micorriza arbuscular. In: VARGAS, M.A.T.; HUNGRIA, M. (Ed.). Biologia dos solos dos Cerrados. Planaltina, DF: Embrapa-CPAC, 1997. p.67-111.

NAHAS, E.; CENTURION, J.F.; ASSIS, L.C. Efeito de características químicas dos solos sobre os microrganismos solubilizadores de fosfato e produtores de fosfatases. Revista Brasileira de Ciência do Solo, v.18, p.49-53, 1994a.
NAHAS, E.; CENTURION, J.F.; ASSIS, L.C. Microrganismos solubilizadores de fosfato e produtores de fosfatases de vários solos. Revista Brasileira de Ciência do Solo, v.18, p.43-48, 1994 b.

PAUL, E.A.; CLARK, F.E. Soil microbiology and biochemistry. San Diego: Academic, 1996.340p.

RHEINHEIMER, D.S.; ANGHINONI, I.; CONTE, E. Fósforo da biomassa microbiana em solos sob diferentes sistemas de manejo. Revista Brasileira de Ciência do Solo, v.24, p.589-597, 2000.

SATTERTHWAITE, F.E. An approximate distribution of estimates of variance components. Biometrics Bulletin, v.2, p.110-114, 1946.

SINGH, J.S.; RAGHUBANSHI, A.S.; SINGH, R.S.; SRIVASTAVA, S.C. Microbial biomass acts as a source of plant nutrients in dry tropical forest and savanna. Nature, v.338, p.499-500, 1989.

SMITH, S.F.; READ, D.J. Mycorrhizal symbiosis. $2^{\text {nd }}$ ed. Cambridge: Academic, 1997. 605p.

SRIVASTAVA, S.C.; SINGH, J.S. Microbial C, N and P in dry tropical forest soils: effects of alternative land-uses and nutrient flux. Soil Biology and Biochemistry, v.23, p.117-124, 1991.

TABATABAI, M.A. Soil enzymes. In: WEAVER, R.W.; ANGLE, J.S.; BOTTOMLEY, P.S. Methods of soil analysis: microbiological and biochemical properties. Madison: Soil Science Society of America, 1994. p.775-883.

TISDALE, S.; NELSON, W.L.; BEATON, J.D.; HAVLIN, J.H. Soil fertility and fertilizers. New York: Macmillan, 1993. 634p.

TORSVIK, V.; GORSOYR, J.; DAEE, F.L. High diversity in DNA soil bacteria. Applied and Environmental Microbiology, v.56, p.782-787, 1990.

TRASAR-CEPEDA, C.; LEIRÓS, C.; GIL-SOTRES, F.; SEOANE, $S$. Towards a biochemical quality index for soils: an expression relating several biological and biochemical properties. Biology and Fertility of Soils, v.26, p.100-106, 1998.

$\overline{\text { Recebido em } 16 \text { de setembro de } 2003 \text { e aprovado em } 19 \text { de março de } 2004}$ 